\title{
Where did my OCD come from? A qualitative exploratory study
}

Åshild Tellefsen Håland, Gunvor Launes, Tor Sunde, Joseph A. Himle, Patrick A. Vogel, Vegard Øksendal Haaland and Liv Tveit Walseth

Clinical impressions suggest that many patients with mental health problems who enter therapy believe that it is important to obtain an understanding of the causes of their disorder in order to achieve lasting relief from their problems. This belief corresponds to assertions from many schools of psychotherapy that claim it is important to explore the underlying causes of a disorder to find a 'cure' for particular problems (Frank, 1971; Hayes \& Wilson, 1993; Ilardi \& Craighead, 1994). This approach, one that involves the creation of meaning in psychotherapy, is considered to be an important therapeutic strategy that decreases symptoms, reduces suffering, and increases self-esteem (Duncan, Miller, Wampold, \& Hubble, 2010; Lambert \& Ogles, 2004; Wampold, 2007).

There is a lack of studies exploring how individuals with obsessive-compulsive disorder (OCD) understand and give meaning to their own diagnosis. However, this overlooked dynamic and other similar issues have been investigated for other diagnoses such as depression (Rønberg, 2016), ADHD (Nielsen, 2016; Young, Bramham, Gray, \& Rose, 2008), and eating disorders (Espindola \& Gray, 2008). Of potential relevance to this paper concerning OCD is a quantitative study on depression that suggests addressing client beliefs about the causes of their depression can positively affect both treatment outcomes and perceived treatment credibility (Addis \& Carpenter, 1999; Addis \& Jacobsen, 1996). Addis and Jacobsen (1996) found that the total number of reasons a client endorses a treatment, regardless identified reasons' content, predicts the type of response he or she will have to a behavioral treatment for depression. Additionally, a patient's specific thoughts about the causes of his or her condition predict differential outcomes of two treatments. Clients who stated existential reasons for depression (e.g., I do not know who I am or what I stand for; I am stuck where I am in life) had better outcomes in cognitive therapy and worse outcomes when offered behavioral activation. Relationship-oriented reasons for depression (e.g., my partner does not understand me; my partner treats me poorly) were consistently associated with negative processes and outcome in CBT. Contrary to the investigators' expectations, childhood-based reasons for depression (e.g., my family treated me poorly as a child) showed no reliable relationship to outcomes in either treatment offered in this study. Given these results for depression, it may be reasonable to assume that different beliefs about what caused a patient's OCD problems may also affect the response to CBT for obsessions and compulsions.

However, contemporary cognitive-behavioral models for OCD do not consider the potential psychosocial causes of OCD as a particularly important factor in facilitating change during treatment. The origin of OCD has been given some attention by cognitive theorists to develop an explanatory theory for OCD, but focusing on the causes of the disorder during treatment is not considered central (Clark, 2004; Frost \& Steketee, 2002; Rachman, 1997; Salkovskis, Shafran, Rachman, \& Freeston, 1999). This belief is reflected in wellknown exposure and response prevention (ERP) manuals for children and adults with OCD (e.g.. Clark, 2004; Foa, Yadin, \& Lichner, 2012; Freeman \& Garcia, 2009; Piacentini, Langley, \& Roblek, 2007; Steketee, 1999). The main focus in ERP is primarily on reducing or eliminating symptoms, not uncovering the potential contributing causes or origins of OCD symptoms. The limited attention that is given in most ERP manuals regarding the causes of OCD typically includes brief psychoeducation focused on the research literature about OCD's etiology with an emphasis on genetics and neurobiology. Little attention, however, is given to psychosocial factors that may contribute to the causes of OCD. Most ERP manuals ask patients to suspend their interest in uncovering the "root" causes of their symptoms. This practice is illustrated in Foa, Yadin, and Lichner's (2012) published ERP treatment manual: "What is important is that this treatment (ERP) does not depend on knowing what caused the 
patent's OCD. Rather, it depends on understanding the nature of the patient's current obsessions and compulsions" (p. 72). Instead of emphasizing the potential origins of patients' OCD problems, most ERP manuals stress the importance of precisely uncovering the current factors that sustain OCD symptoms (e.g., symptom triggers) (Foa et al., 2012).

Although there is considerable evidence supporting the effectiveness of ERP, approximately $50 \%$ of patients with OCD do not respond well to this treatment, and dropouts are common (Cottraux, Bouvard, \& Miller, 2005; Stanley \& Turner, 1995). Thus, there is still room to improve OCD treatment. Because of ERP's reductive and technique-based focus, this form of treatment may not work well for patients who hold the idea that focusing on the causes of their problems is an important aim in therapy. A large mismatch between what patients expect and what they are actually offered in treatment may increase the risk that they will not engage well during treatment. Empirical evidence exists suggesting that poor socialization during treatment, or disagreement with the rationale underlying an intervention, is related to worse treatment outcome for both OCD patients (Daniels \& Wearden, 2011) and patients with other disorders (Addis \& Jacobson, 1996; Addis \& Carpenter, 1999). One potential innovation may be to explore the patient's beliefs about what might have caused his or her OCD problems, at least in some cases. Gaining such an understanding may be relevant because exploration of such reasons may be associated with increased treatment compliance for some patients. It is also possible that this intervention will have no impact for other patients and for still others it may even have a negative impact.

However, we do not know what ideas OCD patients have about why they developed the disorder. To the best of our knowledge, there is only one study in the literature (Murphy \& Perera-Delcourt, 2012) that, among other issues, has explored how individuals with selfidentified OCD from two obsessive-compulsive disorder charities conceptualized the origins of their symptoms. The results from nine semi-structured individual interviews indicated that participants were aware of the impact of their OCD on their life trajectory and traced the disorder back to some early childhood experiences (e.g., distress associated with fitting in with peer groups). A central finding was that the participants experienced a sense of overwhelming personal failure during age-appropriate lifecycle goals. The study also reported that being able to locate the psychological causes of OCD helped patients make sense of it as a clinical disorder.

\section{Aims of study}

Summarized, there are a lack of empirical studies that investigate OCD patients' understanding as to why they developed the disorder. Gaining a deeper understanding into the patients' beliefs about what might have caused their OCD problems is needed. Exploring such beliefs may provide clues that could inform ways to modify ERP treatment to make it more appealing and/or effective. This capability may be particularly useful in retaining patients who enter ERP-based treatment with a desire to explore their thoughts about what factors might have contributed to their OCD problems. The current study aimed to explore OCD patients' understanding of the potential causes of their OCD. It also strove to gain further understanding about the potential significance of having a theory about why patients developed OCD. It is hoped that this qualitative exploratory study will contribute to the OCD field with knowledge beyond what could be discovered using the predefined questionnaires commonly employed in the CBT field. Specifically, we sought to answer the following research questions:

1. Do OCD patients have theories regarding what caused their OCD and, if so, what are they?

2. Do OCD patients have an understanding about the significance of having a theory about why they have developed OCD? 


\section{Method}

\section{Research design}

A hermeneutical-phenomenological approach was selected because it is well established as being capable of revealing how human beings perceive reality (Denzin \& Lincoln, 1994; Malterud, 2012a). We selected the focus group interview as the data collection strategy to stimulate reflections among other peers with similar problems (Malterud, 2012a). For the data-analytic strategy, we employed the systematic text condensation (STC) method developed by Malterud (2012b), which in turn is a modification of Giorgi's (2009)

phenomenological methodology. STC was selected because it is a pragmatic data-analytic strategy for explorative studies. It allows an open-minded approach without applying predefined frameworks.

\section{Researchers}

The present study is part of a qualitative and quantitative study titled "The Norwegian longterm OCD project" (Sunde et al., 2017; Walseth, Haaland, Launes, Himle, \& Haaland, 2017; Walseth, Walseth, Haaland, Launes, Himle, \& Haaland, 2017). All authors except the sixth (Øksendal Haaland) and last (Walseth) are highly experienced CBT therapists, with special expertise in ERP treatment for OCD. All had clinical experiences in other treatment approaches as well. The second and last authors (Launes and Walseth) are medical doctors while the others are licensed clinical psychologists. Although all authors hold interest in and have some experiences with qualitative research, only Walseth is a highly experienced qualitative researcher. Walseth therefore held the main responsibility for the focus group interviews and was closely involved in the analytic process as well.

The first author (Haaland) and the second author (Launes) played a dual role as both cointerviewers and therapists in the original group ERP. Launes also treated some of the patients after they completed group ERP. In the study's planning, the investigative team discussed whether to include a question about the patients' understanding of why they developed OCD. It was argued that asking about the origin of OCD might elicit guilty feelings from some participants (e.g., if they blamed others for their OCD), which could be unnecessarily stressful. This potential concern notwithstanding, the team, relying on its substantial clinical experience, decided to include the question. They believed that patients could manage distress associated with the question. They also felt that the question could reveal important patient beliefs about how OCD symptoms might stem from other underlying problems, especially for patients who did not respond to ERP.

\section{Participants}

During the period from 2003 to 2009, 65 patients participated in an open 12-week trial of group behavioral treatment for OCD (Håland, Vogel, Lie, Launes, Pripp, \& Himle, 2010; Håland, Vogel, Launes, Haaland, Hansen, Solem, \& Himle, 2011). The original inclusion criteria for the study included: age ranging from 18 to 65 years; a primary diagnosis of OCD obtained via the Structured Clinical Interview of the DSM-IV (SCID-1; First, Spitzer, Gibbon, \& Williams, 1995); and a score of 16 or more on the Yale-Brown ObsessiveCompulsive Scale (Y-BOCS; Goodman et al., 1989). The exclusion criteria encompassed current psychotic disorder, current alcohol or drug abuse/dependence, high suicidal risk, and current benzodiazepine medication use.

In 2014 and 2015, all patients who could be reached from the original study ( $N=65)$ were asked to participate in an extended, long-term follow-up study, the purpose of which was to investigate the status of these patients 8.5 years, on average (range 5-11 years), after 
completing group ERP. Patients who did not respond to an initial invitation letter were approached by a phone call. Forty participants agreed to take part in the quantitative portion of the study (64.5\% response rate). The participants in the quantitative study were assessed with Y-BOCS and several self-report measures. With an aim of recruiting 12 to 15 participants into three focus groups, 20 of the 40 participants were asked to participate in the qualitative part of the study. These patients were purposely selected with the aim of achieving a diverse distribution in terms of gender and age at the extended, long-term followup. We also wanted a diversity in OCD symptoms because we considered it likely that OCD severity could affect the participants' responses. Selective sampling was performed to increase the variance in the answers given to the interview questions. Fifteen of the 20 approached patients agreed to participate. We have limited information about why five potential participants refused to participate in the study, but anecdotally, several cited they were currently too disturbed by their OCD to feel comfortable attending the focus group meeting.

The final sample included five men and ten women. OCD severity measured with Y-BOCS at the concurrent long-term follow-up study varied from 0 to 30 , with a mean value of 15.1 $(S D=10.0)$, indicative of a large diversity in symptom levels. At the time of interview, ten of the participants where defined as responders and five as non-responders. The participants were classified as responders or recovered if their Y-BOCS score decreased by at least eight points from pretreatment to extended, long-term follow-up and if their final Y-BOCS score was 14 or less. The participants whose scores did not improve by more than eight points were classified as unchanged or non-responders. (See Sunde et al., 2017 for more details.) Eleven participants reported that they had received additional OCD treatment after they completed group ERP up to eleven years ago. The reported additional therapy included group and individual ERP, individual nonspecific psychotherapy, and/or supportive treatment delivered by general practitioners and community-based mental health nurses.

The participants were divided into three focus groups with five participants each. Focus groups were assembled based on both a participant's ability to attend meetings on a particular day and time and the creation of a diverse group of participants, as mentioned above. Although the composition of the groups was, in part, determined by convenience, the all three included both genders and substantial variations in current Y-BOCS scores. Such scores ranged from 8 to 22 in the first group, 4 to 30 in the second group, and 0 to 28 in the third group. To protect the anonymity of the participants, a more detailed description is omitted. The participants are referred to by pseudonyms when they are quoted in the Results section. Participants were compensated with 500 Norwegian kroner (approximately 60 U.S. dollars) for participating in the focus interview.

Information power. We consider the current study to have high information power. Malterud, Siersma, and Guassora (2015) define information power as an indication of the amount of information a relevant group/individual holds. When information power is high, fewer participants are needed to gather sufficient information in a qualitative study. The three researchers suggest that determinations about whether a given sample is sufficient depend on whether the study: (1) has a specified and narrow aim; (2) includes participants holding characteristics that are highly specific for the study aims; (3) exhibits a strong and clear dialogue between researchers and participants; and (4) has a suitable framework and method of analysis. When the information power is high, 8 to 10 participants are considered an appropriate sample size (Malterud et al., 2015). Our study is in line with these abovementioned dimensions, indicating that our sample size of 15 was adequate. 


\section{Data collection}

Interviews. The interviews took place at an outpatient clinic. They were led by Walseth, with Haaland and Launes serving as co-interviewers. Because the co-interviewers had a dual role as both interviewers and therapists, their role during interviewing was downplayed in that the main interviewer (Walseth) asked most of the questions and was primarily responsible for the dialogue. As a means of preventing social desirability, the main interviewer initially emphasized the importance of participants expressing both positive and negative experiences from their specific point of view. Critical feedback was explicitly welcomed, and it was highlighted that no right and wrong answers existed.

Focus groups were chosen over individual interviews because such an approach is suitable in stimulating the group dynamic by soliciting participants to reflect together. We also considered that familiarity with the two co-interviewers might increase the chance for participants being able to talk about potentially sensitive topics in a group setting.

The interviewers endeavored to ask open-ended questions and encouraged the participants to talk to each other. When the participants' answers were vague or too general, the interviewers asked for more details and concrete examples. In all three focus groups, the interaction among the participants was experienced as supportive, where one often added nuances to another's statements. The three focus group interviews were completed within a month. Each interview lasted from 90 to120 minutes and was audiotaped and transcribed verbatim by a scientific assistant. Nonverbal phenomena such as pauses and laughter were included to increase the validity of the written material (Mishler, 1984).

In all focus groups, participants were asked questions about their own understanding of why they developed OCD. After the first interview, the interviewers discussed their experiences and refined the interview guide accordingly. This approach enables adjusting to the participants' experiences rather than the researchers' preconceptions. Based on the experiences from the first interview, a question about the patients' understanding of the significance of having a theory about why they developed OCD was added to the interview guide. Several of the participants brought up this topic in an unsolicited way in the first interview, prompting the addition of the question. Participants were also asked questions concerning other topics, which are presented elsewhere (Walseth et al., 2017a, 2017b). We interviewed each group once, and participants were not given the opportunity to comment on the transcripts.

\section{Data analysis}

Systematic text condensation (STC) was applied in the data analytic process. STC is a modification of Giorgi's phenomenological method developed by Malterud (2012b) and included the following steps. The material was first read to gather a general impression of the participants' experiences of why they developed OCD. Next, researchers read the transcripts more closely, searching for units of meaning that represented different aspects related to the research questions. These units of meaning were categorized, and the investigators developed codes for each category. The computer program NVivo 10 (QSR, 2015) was used as an aid in categorization. The content of each of the coded groups were then condensed. Finally, each of these condensates were abstracted and described as new concepts, which represent the results. The results were validated by re-reading the material, ensuring that patients' voices were as accurately reflected as possible.

During the data analysis, the most overarching finding, that of OCD as a coping strategy, became more and more evident. Several of the initial codes were ultimately incorporated into this code. For example, at first, we had a code where OCD was considered as a result of 
stressful life events. We divided these events into sub-themes, such as "too much responsibility for family members" and "lack of possibilities to talk about situations."

It turned out that the code "stressful life events" largely overlapped with a code where we considered OCD as a coping strategy. Likewise, we had a code where the presence of OCD was regarded as a result of personality traits such as perfectionism and high sensitivity. These reasons for the disorder also overlapped with OCD as a coping strategy and could be better understood as a way to master difficult life events.

The first author carried out the initial structuring of the data material, the coding, and the abstraction, with the last author critically auditing the various steps. In the analysis, we critically examined the tentative meaning patterns and refined them through an iterative dialogue with the other co-authors as well

\section{Ethical considerations}

The study was approved by The Regional Committee for Medical and Health Research Ethics in Norway (ref: 2013/1210). The participants were given written and verbal information about the general aims for the study prior to the focus groups. They were given the opportunity for a follow-up consultation, but no one needed this consult. As far as we could observe, the concerns we had beforehand, chiefly that it would be too stressful to talk about potential causes of participants' OCD, were not confirmed. Our overall impression was that participants enjoyed talking about the origins of their OCD. In fact, we were surprised by their reflectivity and openness. We assumed that familiarity with the therapists facilitated openness. No participants withdrew from the study after the interviews.

\section{Results}

Considering the first research question about participants' understanding of why they developed OCD, the data analysis revealed the following main categories: (1) OCD as a coping strategy and (2) OCD as a result of family heritage. Regarding the second research question wherein participants were asked about the significance of having a theory about the origin of OCD, the following categories emerged: (3) comfort in understanding where one's OCD comes from and (4) ambivalence about focusing on causes in OCD treatment. Depending on the richness of the material, the nuances in each category are elaborated upon below.

\section{$O C D$ as a coping strategy}

The most overarching finding related to patients' understanding of why they developed OCD was that many participants regarded their OCD as a coping strategy. They believed that OCD became their solution to coping with helplessness and bad feelings triggered by a range of unmanageable life situations. The unmanageable life situations typically occurred in childhood or late adolescence and were generally associated with concrete events.

Examples of difficult life events included death or suicide attempts by close family members, mental disorder or alcohol abuse in parents, conflicts in family of origin, bullying at school, family chaos, and/or family enmeshment. The severity of the difficult life situations varied greatly, but what characterized many of them was participants' experience of powerlessness and helplessness with few alternatives for appropriate adaptation and coping. 
However, considerable variation existed with respect to how explicitly participants talked about OCD as a coping strategy. In some of the statements, OCD was explicitly described as a coping strategy, whereas in others, the coping was described more implicitly. The challenging situations were organized into three subthemes: (1) control over helplessness, chaos, and uncertainty; (2) reaction to taboos; and (3) reaction to fear. These three subthemes are not mutually exclusive but rather can overlap to some extent.

Control over helplessness, chaos, and uncertainty. The word 'control,' or similar terms, was frequently used to describe the function of participants' OCD symptoms. Several of the participants mentioned that their OCD symptoms were something concrete and controllable in contrast to an uncontrollable life situation. One participant described how her OCD became a way to regulate negative emotions related to a single situation she experienced as threatening and uncontrollable:

In retrospect, it was a challenging life event that triggered [the OCD]. Performing rituals became a way for me to feel in control, because in relation to what had happened, I felt like I had no control. The OCD became a sort of substitute for a painful feeling inside of me .... It became a survival strategy to be able to keep going. (Silje)

Other participants had memories of more than one specific episode and described their struggle to regulate negative emotions in a more or less permanent stressful life situation. They expressed their lack of appropriate tools to handle an uncontrollable and unpredictable life situation. They also indicated that their OCD symptoms became a solution to regulate negative emotions. Such developmental experiences seemed to precede their OCD symptoms, as described below:

When my father was drunk, I got the responsibility for my younger brother .... I do not know if the feeling of not being in control of my own situation might have contributed to me getting OCD .... I had very little control over my own situation. I did not dare tell my mother. I did not dare ask my dad to quit drinking. All I could do was grit my teeth together and bear it as best as I could .... When I was going through these periods I think the feeling of helplessness may have had something to do with my [OCD]. (Sofie)

This is an example of how a participant was overwhelmed by negative emotions within a difficult stressful life situation and where the OCD rituals became a way to gain control. Her ability to exert control over the situation was perceived as small, and rituals became a way to deal with her helplessness. However, as shown in the quotation below, she was fully aware that the coping strategy was inadequate:

So it always felt like I was in some state of panic. It was not a calm thought, that if I just do this or that .... I was just trying to keep my head above water rather than actually thinking it would help to check the stove. (Sofie)

The participant acknowledged that the rituals were maladaptive and irrational, but nonetheless she felt forced to perform them in order to gain control over painful feelings. Gaining control over feelings was also explicitly verbalized by another participant who experienced much chaos and no rules during childhood:

I experienced a lot of painful things, and the $O C D$ was a reaction to that (pain) many years later .... With my parents there were no rules. So I had to make up my own. It was always messy and never any order. That I had to exercise a lot and do things in certain ways I see as issues connected to my (OCD) .... When you experience a lot of chaos on the inside, you have to keep the order in some other way. (Hildegunn) 
The participant described the OCD as a delayed reaction many years after an upbringing in a chaotic home. The rituals literally became a concrete way to make order out of inner emotional chaos caused by external chaos. Performing rituals would prevent the participant from sliding into the kind of mayhem she had experienced as a child. Similarly, another participant also highlighted how performing rituals became a concrete and visible way to gain control over difficult feelings. In contrast to the above-mentioned quotation, the need to have control was not related to upbringing or other adverse external events. Rather, it was related to a general inner uncertainty in adolescence:

It was more of an insecurity in my adolescence that triggered [the $O C D$ ] ... a need to have something concrete to do, because I was so uncertain about many other things. And washing was something concrete. That is my theory on how I started with [the OCD] .... Washing is a way to gain control. It is something tangible, something you can see .... (Tobias)

Reaction to taboos. Other examples that triggered a feeling of helplessness and a need to perform rituals were situations characterized by taboos and limited opportunity to talk about negative emotions. One participant explicitly described how OCD was linked to her brother's death and to the lack of opportunity to talk about the traumatic event after it happened:

I know when it started. I was 15 years old and my brother was 14 when he died. That is when I was introduced to death. "Hush, hush, do not speak about death." It was like that all the time. "Do not talk about it." I had thousands of questions, but I had to keep them inside .... And I became afraid of death, and everything. That was when [the OCD] started. (Karen)

From her point of view, not being able to verbalize negative emotions was associated with the development of OCD symptoms. The disorder can be seen as a coping strategy, although maladaptive. Similarly, another participant described how an upbringing with a mentally ill father and the taboo of talking about the father's illness were linked to the development of OCD:

I think what triggered [the OCD] was that my father, whom I loved very much, was hospitalized at a psychiatric department. He was hallucinating and became very agitated, crying that I could not leave him. I was 18 or 19 years old at the time. And the next day, he tried to commit suicide. When I was about 20 years old, he got worse and would call me and threaten with the same things [suicide]. Then, the OCD started .... I think that when you live in a home where people are very sick, you tiptoe around. As a kid, I do not think you learn to set boundaries for yourself .... Eventually you become ill. I think I had far too much responsibility too early .... But the problem was that it [her father's illness] was never talked about. No, we have never talked about those things. (Beate)

Reactions to fear. While several of the participants reported that the OCD was a means of coping with helplessness triggered by family chaos with limited rules, others' emphasized that the disorder was more of a way to cope with too many rules and fear of making mistakes. Several participants shared that they were exposed to substantial anger in their family of origin. They reported that the aggression and criticism made them very afraid to do something wrong and they were therefore preoccupied with trying to do things perfectly. One of the participants explained how being brought up in a confrontational home triggered his OCD:

Yes, there was a lot of noise and arguing at home. Sometimes I would be caught in between my parents. Perhaps the worst was the scolding. If I had done something wrong, I really heard about it. I feel that the OCD started because of this. (Christopher) 
Although the participant in the above-mentioned quotation was talking about what he thought started his OCD, the quote also suggested that OCD was used as a way to cope with a family climate of arguing and fear of making mistakes. In line with this, another participant linked the fear of punishment as an important reason why she thought she developed OCD:

The environment I was brought up in played a role [in the development of my OCD]. The feeling of being good enough and being comfortable with yourself. If it is present, I think you will be all right in a way. However, if you are punished you become cautious to do everything correct. So I grew up to be excessively concerned about doing everything right, that I should be nice, and good, and make no mistakes. (Eli)

For these participants, excessive perfectionism appeared to develop as an attempt to avoid criticism and punishment. To do things overly correctly might have started as a coping strategy to avoid aggressive reactions but evolved into extensive rituals. Such patients' ability to adequately cope with their parents' anger and criticism seemed not be present in their repertoire. Thus their rituals became perhaps their best available coping strategy.

\section{$O C D$ as a result of family heritage}

The data analysis also revealed a second category, named 'OCD as a result of family heritage', that described other aspects of some participants' understanding of why they developed OCD. It differed with regard to whether participants talked about this factor alone or in combination with others when coping with diverse kinds of life stress. A few of the participants mentioned mental disorders experienced by close relatives to be one of the factors related to the origin of their own OCD:

Sometimes I feel as if it's hereditary or that I almost inherited it since I am so much like my father and his family [a family with a lot of mental disorders and alcoholism]. (Sofie)

At the same time, I think I was genetically predisposed. On my mother's side, there were a lot of anxiety disorders present. (Silje)

Only one of the informants reported close relatives with primarily the mental disorder of OCD as a main reason for his own OCD:

I have inherited much of it from my mother [who had OCD] .... It is in the genes and somewhat in the environment as well. Everything had to be neat and meticulous. She raised us to be like her. And she scolded us if we did not live up to her standards. We mostly did what she wanted. (Øyvind)

According to this participant, his OCD was associated with family heritage as well as perfectionism, fear of making mistakes, and punishment, as expounded above.

\section{Comfort in understanding where my OCD comes from}

Some of the patients expressed comfort and meaningfulness in having an understanding of why they developed OCD. Gaining an understanding and acceptance of the development of the disorder was described by one participant as something that eased the symptoms: I think there can be comfort in finding a cause. Although it does not fix the compulsions, it has been a comfort to figure out these things. I know that what happened to me in adulthood triggered [the OCD] getting really worse. I find it comforting that things are interrelated in one way or another. Perhaps there is a degree of control in that too. (Silje) 
The same participant also stressed that finding a subjective explanation for her OCD positively affected her self-esteem, as the following quote suggests:

I know or I have come to the realization that having a cause makes me feel more confident and secure about myself today. (Silje)

Another participant described how an understanding of her own vulnerability underlying the OCD symptoms helped her to accept herself:

It has helped me to acknowledge the fact that I am what you would call highly sensitive. And I take that somewhat seriously. It helps me to find (my way) back to something in myself that perhaps did not get to unfold in my childhood. It helps me accept that I am not necessarily as callous and tough as the others. (Tora)

However, many of the participants did not say anything about what it meant to them to have a theory about why they had OCD.

\section{Ambivalence about focusing on causes in the treatment of OCD}

The importance of focusing on the origin of OCD in treatment appeared to vary among the participants. Some patients suggested that discussing the causes of the disorder should be added to CBT. Others preferred not to talk about them. One of the participants expressed that focusing on understanding the reasons behind her OCD was not important. She was happy that therapists did not try to investigate the reasons and instead focused on improving current symptoms. As Karen expressed: "For my part it did not matter, because I feel like [the $O C D$ ] came out of the blue. I was most concerned about working with my problems and not the reasons behind them." What emerges in this statement is that she, in contrast to most of the participants, had no conception of a particular reason for her OCD. This lack of conception might explain her lack of interest in focusing on causes for the sake of treatment. However, focusing on the underlying problems behind the symptoms while in treatment was important for some of the participants. This sentiment is expressed by one of the participants:

If one has a good conversation with someone and talks about painful issues, it is just as if the OCD disappears. There is something about that .... One can work not exclusively with the OCD but also with the underlying issues. (Hildegunn)

Several participants expressed their satisfaction with a treatment focusing on reducing symptoms. In addition, however, they suggested more attention be paid to underlying problems:

One way to think about this is to work purely pragmatically to get rid of the compulsions. However, another way of thinking, that some may be reluctant to do ... is to examine deeply what might have triggered it .... One should perhaps take it seriously and talk a little bit about it, for example in a treatment situation. In addition to doing exposure exercises, have some kind of balance between them [exposure exercises and focus on causes]. I do not think one can find one cause, because I think it (OCD) is very complex. (Tobias)

Some participants noted that the possible underlying causes of their OCD were downplayed in previous treatment. Several of the participants expressed a desire that more attention had been given to the causes of their OCD in their previous treatment. This wish was expressed by the same participant as above: 
It would have been nice to at least have the opportunity to open up about [causes]. In [a former therapy], I got the opportunity to talk about it, but it was not explored further .... I think maybe at that point, it would have been a good idea to emphasize it a little more .... I do not believe one should ignore certain potential causes. One should possibly take it more seriously and talk about it. (Tobias)

Although some wanted more focus on causes, other participants seemed to want to avoid saying anything negative about the group ERP treatment they received many years ago.

\section{Discussion}

The first aim of this study was to explore OCD patients' understanding of why they developed the disorder. Overall, the results showed that many patients had rich hypotheses concerning why they developed OCD. The overarching finding was that many of the participants regarded OCD as a coping strategy wherein the rituals served as a way to manage different types of situations. These situations were characterized by a need to control chaos, uncertainty, and a feeling of helplessness, taboos, limited opportunity to talk about negative emotions, and fear of anger and punishment from close relatives. Another potential cause linked to the development of OCD identified by some participants was family heritage.

The second goal of this study was to explore the OCD participants' understanding of the significance of having a theory about why they developed OCD. The qualitative data revealed that some of the participants emphasized having an understanding of the meaning behind the symptoms was comforting and strengthened their self-esteem. Although the majority had many explanations for the origin of their OCD, the importance of focusing on this issue in treatment varied among the participants. Some participants suggested that discussing the causes should be added to CBT whereas others preferred not to talk about them.

To our knowledge, this is the first empirical study to report that many patients first perceived their OCD as having developed as a coping strategy. Murphy and Perera-Delcourt (2012) reported that some participants traced the origin of their OCD back to early childhood experiences, but the participants did not explicitly describe the origin of their OCD as a coping strategy for mastering difficult past experiences. Although we were unable to locate empirical studies showing that OCD symptoms could be understood as a coping strategy, several researchers have highlighted, from a theoretical perspective, that early adverse experiences might give rise to OCD symptoms. For example, both Rachman (1997) and Salkovskies, Shafran, Rachman, \& Freeston, (1999) have theorized that OCD symptoms are more likely to occur when an individual is exposed to stressful situations (e.g., traumatic and/or aversive events). This conjecture resonates with the current findings in which several participants described a variety of early adverse experiences they assumed to underlie their OCD symptoms. The current results also indirectly support a number of studies that have found the onset of OCD symptoms is associated with the onset of life stressors. Examples include becoming a new parent or exposure to traumatic events (Abramowitz, Khandker, Nelson, Deacon, \& Rygwall, 2006; Cromer, Schmidt, \& Murphy, 2007).

Several researchers in the OCD field have also highlighted the central role concept of control plays within the disorder, which is closely related to coping. (Clark \& Purdon, 1993; OCCWG, 1996; Purdon \& Clark, 2002). However, the research focus in the OCD field has mainly been restricted to individuals' need to control their thoughts rather than focusing 
on controlling emotions or difficult situations. To gain a better understanding of why individuals feel an excessive need to perform rituals, several researchers have called for a research that extends beyond the control of thoughts and beliefs to a greater focus on more general beliefs regarding control (Moulding \& Kyrios, 2006; Doron \& Kyrios, 2005; Sookman \& Pinard, 1999). An example of such research is a study by Mouldning and Kyrios (2007) who found that individuals with a greater need to exert control over events in their lives (desire for control), combined with a low evaluation of their level of control (sense of control) over a situation, have a greater tendency to experience anxiety and regain their sense of control via rituals. This result is somewhat similar to the findings in the current study in which several participants expressed a low sense of control and a high desire to control feelings and situations. An important difference, however, is that Moulding and Kyrios (2007) describe levels of control in current situations whereas this study focuses on the sense of control as it relates to past situations.

Our results related to OCD as a coping strategy also resonate with theoretical and empirical research from other areas within psychology. Therein, different conceptualizations of control (e.g., sense of control, fear of losing control, locus of control, desire of control, and mastery) have been postulated to play a central role in the etiology and maintenance of mental disorders (Bandura, 1989; Shapiro, Schwartz, \& Astin, 1996). This applies, for example, to eating disorders where a perceived lack of control is regarded as a major contributing factor to the development of the disorders (Espindola \& Blay, 2009; Froreich, Vartanian, Grisham, \& Touyz, 2016). Many patients with eating disorders recalled starting dieting at a time when they perceived their lives to be chaotic and out of control (Patching \& Lawler, 2009). This tendency is in line with our results wherein some individuals reported their OCD began or worsened during such times. Control also appears to be of importance in depression and anxiety disorders where the symptoms, at least in part, are regarded as attempts to cope with generalized feelings of perceived lack of control in the early environment (Chorpita \& Barlow, 1998; Shapiro et al., 1996).

The second category, family heritage related to the origin of OCD, indirectly supports a large literature emphasizing family factors as contributing to the development and maintenance of OCD (Hanna, Himle, Curtis, \& Gillespie, 2005; Salkovskis \& Forrester, 2002). Studies have suggested that parents with OCD might contribute to the development of the disorder in their offspring through their participation in compulsive rituals and/or modeling of avoidance, caution, and/or fearfulness (Black, Gaffney, Schlosser, \& Gabel, 2003).

The third category, comfort in understanding where one's OCD comes from, proved consistent with the study by Murphy et al. (2012). They also reported that the ability to locate the psychological cause of OCD helped patients make sense of their symptoms. Similar to our results, several of their participants also reported that discovering potential causes for their OCD was important to them and potentially helpful. Our participants reported that gaining an understanding of the meaning of their OCD was both comforting overall and somewhat helpful in reducing OCD symptoms. This takeaway corresponds to assertions from well-established researchers (Duncan, Miller, Wampold, \& Hubble, 2010; Lambert \& Ogles, 2004; Wampold, 2007; ) who claimed approaches that involve the creation of meaning in psychotherapy affect self-esteem positively and reduce overall suffering.

Of relevance to the current findings is the theoretical formulation sense of coherence, developed by Aron Antonovsky $(1979,1996)$. One important element in sense of coherence is an anticipation that things happen in an orderly and predictable fashion. It involves a sense that events in life are understandable and can be influenced. Antonovsky found that people 
with a high sense of coherence are better prepared to endure life hardship (Antonovsky, 1996). Most participants in the current study gained at least some understanding of the meaning behind their OCD symptoms. They did not believe that the symptoms came out of the blue. Rather, they believed that the symptoms were present, at least in part, as reactions to diverse unmanageable life events.

The fourth category, ambivalence focusing on causes in ERP treatment, has not been described previously in qualitative studies, even though many therapists have experienced this issue during treatment. Although most participants expressed beliefs about why they developed OCD, the significance of this issue in terms of treatment varied from participant to participant. It is noteworthy that most participants in the current study recognized the value of ERP and were satisfied with the group behavioral treatment they received (Walseth et al., 2017). Although the majority found ERP useful, some called for more attention to potential causes of their OCD in treatment. In contrast, others were ambivalent about including it and some regarded it as unnecessary.

\section{Clinical implications}

Clearly, it remains an open question whether increasing attention to the potential causes of OCD during treatment, with the primary focus on ERP, will improve treatment outcomes. It is possible that taking time to discuss potential causes of OCD, including exploring the meaning behind the symptoms, will attenuate the effect of ERP and not increase it. This may be a particular challenge if such discussions occurred prior to conducting exposure exercises. That is because these discussions might uncover patients' avoidant tendencies and potentially delay useful exposures. Conversely, it may be that paying more attention to the potential causes of OCD may increase treatment effects, especially for non-responders. In particular, it might be useful to explore if non-responders regard their OCD as a coping strategy to deal with difficult and unmanageable prior or ongoing life situations. Under such circumstances, it may be desirable to augment ERP with additional types of therapy. Such treatment additions may assist the individual in developing new, more adaptive coping skills or insights to address ongoing, challenging life circumstances (e.g., schema therapy, trauma therapy).

As outlined in the introduction, low adherence to manualized procedures in ERP treatment is associated with reduced outcomes (Daniels \& Wearden, 2011). To reduce the risk of poor socialization to treatment, it may be best to match the amount of attention paid to OCD's causes to the preferences of the patient. Simply asking a question early in treatment about how important it is to the patient that their therapy addresses the causes of OCD, may be a good way to judge how much attention to give to this issue. Taking into account these preferences may reduce risks of early dropout and/or poor treatment adherence.

\section{Strengths and limitations}

The experiences revealed in this study concern a cohort of patients who were interviewed between five and 11 years after attending group therapy and are not necessarily generalizable to patients who recently received treatment. Nor are they necessarily applicable to those who have not received treatment at all. The participants in the current study had years to reflect upon potential causes of their OCD. This long period of time may have increased the amount of reflection on this issue. A strength of this study is that participants were representative of the typically referred outpatients, thus making our results more applicable to the usual context in which treatment is provided. 
challenging if the discussion involves negative comments about close relatives. Thus, the focus group setting may have limited the depth of reflections on sensitive family issues. This potential issue notwithstanding, our focus group participants were seemingly quite candid on a range of sensitive family-related issues. However, we cannot rule out that individual interviews would have provided more information on potentially sensitive topics related to the origins of OCD. Conversely, an advantage of focus groups is that conversations among participants can produce rich dialogue and multifaceted reflections, and these reflections may not have occurred in individual interviews.

Another limitation is that negative comments about ERP treatment may have been suppressed because of participant concerns about offending their former therapist(s). The dual role as both co-interviewer and therapist in the original group might make it less likely for participants to offer critical remarks about the therapy they received. Conversely, the fact that two of the interviewers knew all of the patients may have made them feel safer in the group and thereby may have facilitated the conversation. It is important to note, however, that in the spirit of mutual exploration aimed at improving treatment for OCD, participants were encouraged to talk freely about any concerns they had regarding their previous treatment.

\section{Future research}

The current results may stimulate several interesting quantitative research projects. One opportunity involves investigation into how common it is for individuals with OCD to perceive their OCD symptoms as a way of coping with or controlling difficult emotions and stressful life situations. Furthermore, it would be interesting to investigate whether different levels of perceived control in both the past and present would affect the severity of current OCD symptoms. Would, for example, non-responders and dropouts report a greater lack of control of life in general compared to those who respond to treatment? Another possible implication is that the current results may lay a foundation for developing a questionnaire regarding perceived reasons for acquiring OCD. Similar to the depression study by Addis and Jacobsen (1996) mentioned in the Introduction, it would be interesting to investigate whether different perceived reasons for OCD are associated with different patient outcomes. The current findings could also form a basis for a pilot test of the utility of an enhanced version of ERP that includes attention to the use of OCD as a coping strategy to handle difficult life situations. Another research approach could be to investigate whether exploring potential reasons for the development and maintenance of patients' OCD symptoms before the start of ERP would positively affect treatment outcomes.

\section{Conclusion}

As outlined in the Introduction, cognitive-behavioral models for OCD do not emphasize the exploration of potential psychosocial causes of the disorder. Our findings indicate that at least some OCD patients are very interested in exploring beliefs about the origins of their obsessive-compulsive problems during treatment. Participants noted a range of potential psychosocial contributors to the development of their OCD symptoms. Of particular note were beliefs that OCD initially developed as a coping strategy for handling difficult life situations.

Additionally, the creation of meaning through exploration of potential OCD causes was mostly experienced by participants as a comforting process. Some participants, however, 
expressed ambivalence about whether it was useful to devote time to discussing the origins of their OCD during behavioral treatment.

Finally, given that a significant minority of OCD patients either refuse, drop out, or fail to respond to CBT for OCD, it is possible, at least for some patients, that spending time in therapy exploring beliefs about the causes of one's OCD and potentially helping a patient learn more adaptive ways to cope with difficult life circumstance may make CBT both more appealing and effective.

\section{References}

Abramowitz, J. S., Khandker, M., Nelson, C. A., Deacon, B. J, \& Rygwall B. (2006). The role of cognitive factors in the pathogenesis of obsessive-compulsive symptoms: A prospective study. Behavior Research and Therapy, 44(9), 1361-1374. doi:10.1016/j.brat.2005.09.011

Addis, M. E., \& Carpenter, K. M. (1999). Why, why, why? Reason-giving and rumination as predictors of response to activation- and insight-oriented treatment rationales. Journal of Clinical Psychology, 55, 881-894. doi: Addis, M. M., \& Jacobson, N. S. (1996). Reasons for depression and the process and outcome of cognitive-behavioral psychotherapies. Journal of Consulting and Clinical Psychology ${ }_{2} 64,1417-1424$.

Antonovsky, A. (1979). Health, Stress, and Coping. San Francisco, CA: Jossey Boss.

Antonovsky, A. (1996). The salutogenic model as a theory to guide health promotion. Health Promotion International, 11, 11-18, doi:10.1093/heapro/11.1.11

Bandura, A. (1989). Perceived self-efficacy in the exercise of personal agency. British Psychological Society, 10, 411-424. doi:10.1080/10413209008406426

Black, D. W., Gaffney, G. R., Schlosser, S., \& Gabel, J. (2003). Children of parents with obsessive-compulsive disorder: A 2-year follow-up study. Acta Psychiatrica Scandinavia, 107, 305-313. doi:https://doi.org/10.1034/j.1600-0447.2003.02182.x

Cottraux, J., Bouvard, \& Miller. (2005). Combining pharmacotherapy with cognitive behavioural interventions for obsessive-compulsive disorder. Cognitive Behaviour Therapy, 34, 185-192. doi:10.1080/16506070510043750

Clark, D. (2006). Cognitive-Behavioral Therapy for OCD. New York, NY: Guilford.

Clark, D., \& Purdon, C. (1993). New perspectives for a cognitive theory of obsessions. Australian Psychologist, 28, 161-167. doi:10.1080/00050069308258896

Chorpita, B. R., \& Barlow, D. H. (1998). The development of anxiety: The role of control in the early environment. (1998). Psychological Bulletin, 124(1), 3-21. doi:10.1037/00332909.124.1.3

Cromer, K. R., Schmidt, N. B., \& Murphy, D. L. (2007). An investigation of traumatic life events and obsessive-compulsive disorder. Behaviour Research and Therapy, 45(7), 1683-1691. doi:10.1016/j.brat.2006.08.018

Daniels, J., \& Wearden, A. (2011). Socialization to the model: The active component in the therapeutic alliance? A preliminary study. Behavioural and Cognitive Psychotherapy, 39(2), 221-227. doi:10.1017/S1352465810000792

Denzin, N. K., \& Lincoln, Y. S. (1994). Handbook of Qualitative Research. Thousand Oaks, CA: Sage.

Doron, G., \& Kyrios, M. (2005). Obsessive-compulsive disorder: A review of possible internal representations within a broader cognitive theory. Clinical Psychology Review, 25, 415-432. doi:10.1016/j.cpr.2005.02.002

Duncan, B. L., Miller, S. D., Wampold, B. E., \& Hubble, M.A. (2010). The Heart and Soul of Change: Delivering What Works in Therapy $\left(2^{\text {nd }}\right.$ Ed.). Washington, D.C., USA: American Psychological Association. doi:10.1037/12075-000

Espindola, C.R., \& Blay, S. L. (2009). Anorexia nervosa's meaning to patients: A qualitative synthesis. Psychopathology, 42, 69-80. doi:10.1159/000203339 
First, M. B., Spitzer, R. L., Gibbon, M., \& Williams, J. B. W. (1995). Structured Clinical Interview for DSM-IV Axis 1 Disorders - Patient Edition (SCID I/P, version 2.0). New York, NY: Biometrics Research Department. doi:10.1037/t07827-000

Foa, E. B., Yadin, E., \& Lichner, T. K. (2012). Exposure and Response (Ritual) Prevention for Obsessive- Compulsive Disorder: Therapist Guide ( $2^{\text {nd }}$ Ed.). New York, NY: Oxford University Press. doi:10.1093/med:psych/9780195335286.001.0001

Frank, J. D. (1971). Therapeutic factors in psychotherapy. American Journal of Psychotherapy, 25, 350-361. doi:10.1176/appi.psychotherapy.1971.25.3.350

Freeman, J. B., \& Garcia, A. M. (2008). Family-Based Treatment for Young Children with OCD. Therapist Guide. New York, NY: Oxford University Press. doi:10.1093/med:psych/9780195373639.001.0001

Froreich, F. V., Vartanian, L.R., Grisham, J. R., \& Touyz, S. W. (2016). Dimensions of control and their relation to disordered eating behaviors and obsessive-compulsive symptoms. Journal of Eating Disorders, 4(14), 1-9. doi:10.1186/s40337-016-0104-4

Frost, R. O., \& Steketee, G. (2002). Cognitive Approaches to Obsessions and Compulsions: Theory, Assessment, and Treatment. Amsterdam, Netherlands: Pergamon/Elsevier Science. doi:10.1016/B978-008043410-0/50001-5

Giorgi, A. (2009). The Descriptive Phenomenological Method in Psychology: A Modified Husserlian Approach. Pittsburgh, PA: Duquesne University Press.

Goodman, W. K., Price, L. H., Rasmussen, S. A., Mazure, C., Fleischmann, R. L., Hill, C. L., \& Charney, D. S. (1989). The Yale-Brown Obsessive Compulsive Scale. I. Development, use, and reliability. Archives of General Psychiatry, 46(11), 1006-1011. doi:10.1001/archpsyc. 1989.0181011004800

Hanna, G. L., Himle, J. A., Curtis, G. C., \& Gillespie, B. W. (2005). A family study of obsessive-compulsive disorder with pediatric probands. American Journal of Medical Genetics (Part B Neuropsychiatric Genetics), 135B, 13-19. doi:10.1002/ajmg.b.30138

Hayes, S. C., \& Wilson, K. G. (1993). Some applied implications of a contemporary behavioranalytic account of verbal events. The Behavior Analyst, 16, 283-301. doi:10.1007/BF03392637

Håland, Â. T., Vogel, P. A., Lie, B., Launes, G., Pripp, A. H., \& Himle, J. A. (2010). Behavioural group therapy for obsessive-compulsive disorder in Norway. An open community-based trial. Behaviour Research and Therapy, 48, 457-554. doi:10.1016/j.brat.2010.03.005

Håland, A. T, Vogel, P. A., Launes, G., Haaland, V. Ø., Hansen. B., Solem, S., \& Himle, J. A. (2011). The role of early maladaptive schemas in predicting exposure and response prevention outcome for obsessive-compulsive disorder. Behaviour Research and Therapy, 49, 781-788. doi:10.1016/j.brat.2011.08.007

Ilardi, S. S., \& Craighead, E. (1994). The role of nonspecific factors in cognitive-behavior therapy for depression. Clinical Psychology: Science and Practice, 1(2), 138-156. doi:10.1111/j.1468-2850.1994.tb00016

Lambert, M. J., \& Ogles, B. M. (2004). The efficacy and effectiveness of psychotherapy. In M. J. Lambert (Ed.), Bergin and Garfield's Handbook of Psychotherapy and Behavior Change (5th ed., pp. 139-193). New York: Wiley.

Malterud, K. (2012a). Focus Groups as Research Method for Medicine and Health Sciences. In Norwegian. Oslo, Norway: Universitetsforlaget.

Malterud, K. (2012b). Systematic text condensation: A strategy for qualitative analysis. Scandinavian Journal of Public Health, 40(8), 795-805. doi: $10.1177 / 1403494812465030$

Malterud, K., Siersma, V.D., \& Guassora, A.D. (2015). Sample size in qualitative interview studies: Guided by information power. Qualitative Health Research, 26(13), 1753-1760. doi: $10.1177 / 1049732315617444$

Mishler, E. G. (1984). The Discourse of Medicine: Dialectics of Medical Interviews. Norwood, N.J.: Ablex Publishing. 
Moulding, R., \& Kyrios, K. (2006). Anxiety disorders and control related beliefs: The exemplar of Obsessive-Compulsive Disorder (OCD). Clinical Psychology Review, 26, 573-583. doi:10.1016/j.cpr.2006.01.009

Moulding, R., \& Kyrios, M. (2007). Desire for control, sense of control, and obsessivecompulsive symptoms. Cognitive Therapy and Research, 6, 759-772. doi:10.1007/s10608-006-9086-x

Murphy, H., \& Perera-Delcourt, R. (2012). 'Learning to live with OCD is a little mantra I often repeat': Understanding the lived experience of obsessive-compulsive disorder (OCD) in the contemporary therapeutic context. Psychology and Psychotherapy: Theory, Research, and Practice, 87(1), 111-125. doi:10.1111/j.2044-8341.2012.02076.x

Nielsen, M. (2016). Experiences of ADHD in Adults: Morality, Temporality, and neurobiology. Ph.D.-serien for Det Humanistiske Fakultet, Aalborg Universitet. Aalborg, Denmark: Aalborg Universitetsforlag. doi:10.5278/vbn.phd.hum.00054

OCCWG, Obsessive Compulsive Cognitions Working Group. (1997). Cognitive assessment of obsessive-compulsive disorder. Behavior Research and Therapy, 34, 667-681. doi:10.1016/S0005-7967(97)00017-X

Patching, J., \& Lawler, J. (2009). Understanding women's experiences of developing an eating disorder and recovering: A life-history approach. Nursing Inquiry, 16, 10-21. doi:10.1111/j.1440-1800.2009.00436.x

Piacentini, J., Langley, A., \& Roblek, T. (2007). Cognitive-Behavioral Treatment of Childhood OCD: It's Only a False Alarm Therapist Guide. New York, NY: Oxford University Press. doi:10.1093/med:psych/9780195310528.001.0001

Purdon, C., \& Clark, D. A. (2002). The need to control thoughts. In R. O. Frost (Ed.) \& Steketee, G. (Ed.), Cognitive Approaches to Obsessions and Compulsions: Theory, Assessment, and Treatment. Amsterdam, Netherlands: Elsevier Science. doi:10.1016/B978-008043410-0/50004-0

QSR. NVivo 10 http://www.qsrinternational.com/ http://www.qsinternational.com/2015 [cited 2015 August 24].

Rachman, S. (1997). A cognitive theory of obsessions. Behaviour Research and Therapy, 35, 793-802. doi:10.1016/S0005-7967(97)00040-5

Rønberg, M. (2016). Struggling with a depression diagnosis: Negotiations with diagnostic categories. Nordic Psychology, 69, 5-18. doi:10.1080/19012276.2016.1267915

Salkovskis, P. M., Shafran, R., Rachman, S., \& Freeston, M. H. (1999). Multiple pathways to inflated responsibility beliefs in obsessional problems: Possible origins and implications for therapy and research. Behavior Research and Therapy, 37, 1055-1072. dos: $10.1016 /$ S0005-7967(99)00063-7

Shapiro, D. H., Schwartz, C. E., \& Astin, J. A. (1996). Controlling over selves, controlling our world. Psychology's role in understanding positive and negative consequences of seeking and gaining control. American Psychologist, 51(12), 1213-1230. doi:10.1037//0003066X.51.12.1213

Sookman, D., \& Pinard, G. (1999). Integrative cognitive therapy for obsessive-compulsive disorder: A focus on multiple schemas. Cognitive and Behavioral Practice, 6, 351-362. doi:10.1016/S1077-7229(99)80055-8

Stanley, M. A., \& Turner, S. M. (1995). Current status of pharmacological behavioural treatment for obsessive-compulsive disorder. Behavior Therapy, 26(1), 163-186. doi:10.1016/S0005-7894(05)80089-9

Steketee, G. (1999). Overcoming Obsessive-Compulsive Disorder: A Behavioral and Cognitive Protocol for the Treatment of OCD: Therapist Protocol. Oakland, CA: New Harbinger Publications.

Sunde, T., Walseth, L. T., Himle, J. A., Vogel, P. A., Launes, G., Haaland, V.Ø., Hoffart, A., Johnson, S.U., \& Haaland, A. T. (2017). A long-term follow-up of group behavioral therapy for obsessive-compulsive disorder in a general outpatient clinic in Norway. Journal of Obsessive-Compulsive and Related Disorders, 14, 59-64. doi:10.1016/j.jocrd.2017.06.002 
Wampold, B. E. (2007). Psychotherapy: The humanistic (and effective) treatment. American Psychologist, 62, 857-873. doi:10.1037/0003-066X.62.8.857

Walseth, L. T., Haaland, V.O., Launes, G., Himle, J. A., \& Haaland, Å.T. (2017). Obsessivecompulsive disorder's impact on partner relationships: A qualitative study. Journal of Family Psychotherapy, 28(3), 205-221. doi:10.1080/08975353.2017.1291239

Walseth, L. T., Walseth, A.. M. T., Haaland, V.O., Launes, G., Himle, J. A., \& Haaland, Å.T. (2017). Self-management of obsessive-compulsive disorder in the long-term after therapy: A focus group interview. European Journal for Person-Centered Healthcare, 5(1), 64-74. dos:10.5750/ejpch.v5i1.1209

Young, S., Bramham, J., Gray, K., \& Rose, E. (2008). The experience of receiving a diagnosis and treatment of ADHD in adulthood: A qualitative study of clinically referred patients using interpretative phenomenological analysis. Journal of Attention Disorder, 11, 493-503. doi:10.1177/1087054707305172 